\title{
Severe underreporting of energy intake in normal weight subjects: use of an appropriate standard and relation to restrained eating
}

\author{
I Asbeck ${ }^{1}, \mathrm{M} \mathrm{Mast}^{1}$, A Bierwag ${ }^{1}$, J Westenhöfer ${ }^{2}, \mathrm{KJ}$ Acheson ${ }^{3}$ and M Müller ${ }^{1, *}$ \\ ${ }^{1}$ Institut für Humanernährung und Lebensmittelkunde der Universität Kiel, Düsternbrooker Weg 17-19, D-24105 \\ Kiel, Germany: ${ }^{2}$ Fachhochschule Hamburg, Lohbrügger Kirchstrasse 65, D-2 1033 Hamburg, Germany: ${ }^{3}$ Nestlé \\ Research Center, PO Box 44, CH-1000 Lausanne 26, Switzerland
}

Submitted 23 December 1999: Accepted 20 June 2001

\begin{abstract}
Objective: To assess the influence of different standards and restrained eating on underreporting in healthy, non-obese, weight-stable young subjects.

Design and subjects: Eighty-three young adults (20-38 years, 55 women, 28 men) were assessed under weight-stable conditions with a 7-day dietary record and the three-factor eating questionnaire by Stunkard and Messick. Resting energy expenditure (REE; indirect calorimetry) plus data derived from physical activity records (PA) (Standard 1) or REE times an activity factor (AF) (Standard 2) was used as standard for total energy expenditure (TEE). For comparison, doubly labelled water (DLW) was used to measure TEE in a subgroup of subjects.

Results: There was an association between self-reported energy intake and Standard 2 $(r=0.72)$ but not with Standard 1. When compared with DLW both calculated standards were inaccurate, but Standard 2 avoided high levels of overreporting. Using Standard 2 to identify 'severe' underreporting (SU; as defined by a deviation of energy intake (EI) and TEE of $>20 \%$ ), SU was seen in $37 \%$ of all subjects. It was more frequently found in women than in men ( $49 \%$ of women, $14.3 \%$ of men, $P<0.05$ ). Underreporting subjects had a reduced EI $(P<0.01)$ but there were no significant differences in nutritional status (body weight and height, body mass index, fat mass and fat-free mass), energy expenditure and the proportion of energy from macronutrients between normal and underreporting subjects. However, high restraint was associated with a higher degree of underreporting in the total group, whereas disinhibition had an influence only in men.

Conclusions: A high prevalence of SU is seen in non-obese subjects. Characteristics of eating behaviour (restraint and disinhibition) were associated with underreporting but seemed to have a different influence in men and women.
\end{abstract}

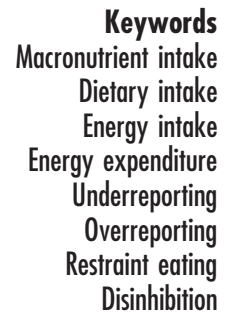

Measurement of dietary intake is difficult and different assessment methods may lead to different results in individual subjects ${ }^{1}$. Underreporting introduces a considerable and unacceptable error in the estimate of energy intake. It is therefore important to find predictors of underreporting. Dietary underreporting has been described in obese subjects ${ }^{2-7}$ but it is also seen in nonobese subjects $^{8-11}$. Underreporting was defined by the use of a reference standard (i.e. measurement of total energy expenditure in weight-stable subjects using doubly labelled water ${ }^{12-16}$ ).

Only a few studies have investigated the effect of psychological aspects of eating behaviour on the assessment of energy intake and dietary underreporting $^{12,17-20}$. All of these studies used the three-factor eating questionnaire by Stunkard and Messick for the assessment of eating behaviour with the exception of Price et al., who described their population in terms of extroversion and neuroticism scores ${ }^{20}$. Poppitt et al. ${ }^{12}$ assessed self-reported energy intake (covertly measured throughout the study, plus records of all food and drink intakes in the previous 24 hours) in 33 women, and found significant underreporting in obese and non-obese subjects. No specific cut-off was used for the definition of underreporting. The results of that study have shown that higher cognitive restraint may also be predictive of a higher degree of underreporting. De Castro et al. ${ }^{17}$, who studied the selfreported energy intake in 201 men and 157 women with 7-day dietary records, showed that in both men and women higher cognitive restraint was associated with lower and less variable overall intake, especially of fat and carbohydrate. In this study no standard of energy intake was measured. Bingham et al. ${ }^{18}$, using doubly labelled water as a measure of total energy expenditure, 
also found higher degrees of underreporting in subjects with higher cognitive restraint. Again no specific cut-off was used for the definition of underreporting. Black et al., who validated energy and protein intakes by doubly labelled water and 24-hour nitrogen excretion in postobese subjects, found that underreporting subjects are restrained eaters ${ }^{19}$

Taken together, all of these studies show that underreporting occurs in obese as well as non-obese subjects. Preliminary evidence supports that a high cognitive restraint is associated with underreporting. Since underreporting was not consistently defined and also standards used to define underreporting differ between the studies, the quantitative influence of psychological aspects of eating behaviour on the phenomenon of underreporting is not fully explained. This study assesses different aspects of eating behaviour as assessed with the three-factor eating questionnaire and their influence on dietary underreporting. For comparison of energy intake energy expenditure was measured and only severe underreporting (i.e. of more than 20\%) was considered.

\section{Methods}

\section{Subjects}

The study was performed with 83 subjects ( 55 women, 28 men) at the Institute of Human Nutrition and Food Science at the University of Kiel, Germany. The study protocol was approved by the local ethics committee. Each subject gave his/her informed written consent at the beginning of the study. The participants were recruited from a student population. Table 1 gives the characteristics of the study population.

\section{Energy intake}

Self-reported energy intake (EI) was assessed using a 7 -day dietary record $(7 \mathrm{dDR})$ with estimated weights of food because of its advantages compared with weighed records (less demanding for subjects, rapid and low-cost assessment of diets, high co-operation rates) ${ }^{21}$. For prepacked food items the weight on the wrapping according to the producer was recorded; all other items were recorded in household measures together with the attributes 'large', 'medium' and 'small'. Self-cooked meals were recorded by noting the recipe and, for milk and milk products, the percentage fat content was also recorded. The subjects were instructed by a nutritionist. The dietary records were analysed using PRODI $4.4^{\circledR}$ (Ernährungs- und Diätberatungsprogramm, Wissenschaftliche Verlagsgesellschaft $\mathrm{mbH}$, Stuttgart) by a trained dietitian.

\section{Nutritional status}

In order to assess the nutritional status, body weight and height were measured (balance beam scale) in light clothing without shoes. All participants were weighed at the beginning of the study and at the end of the protocol week. All subjects were weight-stable $( \pm 0.5 \mathrm{~kg})$ during this week (mean body weight before, $69.9 \pm 12.5 \mathrm{~kg}$; mean body weight after, $70.3 \pm 12.5 \mathrm{~kg}$ ). Body composition was measured by bioelectrical impedance analysis as described previously ${ }^{22}$, using the Body Composition Analyzer TVI-10 ${ }^{\mathrm{TM}}$ (Danninger Medical, Detroit, MI). The computer software developed by Danninger Medical Detroit was used for data analysis (see Table 1 for data on body composition).

\section{Energy expenditure}

Measurements of resting energy expenditure (REE) started 8-12 hours after the subject's last meal. REE was assessed by indirect calorimetry (ventilated hood technique, Metabolic Monitor Deltatrac ${ }^{\mathrm{TM}}$, Datex Division Instrumentarium Corp., Helsinki) as described previously ${ }^{22}$. Three different methods of assessing total energy expenditure (TEE) were compared. First, all subjects wrote an activity protocol for 7 days. Energy expenditure was calculated according to the table 'Energy cost of activity classified in alphabetical order' (World Health Organization ${ }^{23}$ ). TEE was computed by multiplying the time spent in each activity over the day by its energy cost (Standard 1). In order to include $\mathrm{REE}_{\text {measured }}, \mathrm{REE}_{\text {calculated }}{ }^{*}$, was subtracted from TEE and then $\mathrm{REE}_{\text {measured }}$ was added. Second, TEE was calculated from REE $\times 1.55$ as proposed by the $\mathrm{FAO} / \mathrm{WHO} / \mathrm{UNU}^{24}$ (Standard 2). Third, in seven subjects TEE was assessed with the doubly labelled water (DLW) technique (Standard 3). The procedure followed the recommendations of the Consensus Report by the IDECG Working Group ${ }^{25}$. A baseline urine sample was acquired from each subject in fasting state and body weight was assessed in underwear on a balance beam scale. The dosage of the doubly labelled water was $0.15 \mathrm{~g}{ }^{18} \mathrm{O}$ and $0.05 \mathrm{~g}^{2} \mathrm{H}$ per $\mathrm{kg}$. The first urine sample was obtained after 6 hours, and, on the following 12 days, one urine sample was collected daily at around the same time. During these 12 days the subjects wrote a dietary record with estimated weights of food. The analysis was carried out in the Nestlé Research Laboratories, Lausanne. Urine samples were analysed for ${ }^{2} \mathrm{H}(\mathrm{D})$ and ${ }^{18} \mathrm{O}(\mathrm{O})$ as described previously ${ }^{26}$. Energy expenditure was calculated from D/O ratios according to Elia ${ }^{27}$ after correcting the water and carbon dioxide outflow rates for water fractionation ${ }^{25}$.

${ }^{*} \mathrm{REE}_{\text {calculated }}$ was calculated according to the prediction formula of Harris and Benedict for the calculation of energy expenditure:

$$
\begin{aligned}
\text { Men }: & 66.5+13.8 \times \text { body weight }(\mathrm{kg})+5 \\
& \times \text { body height }(\mathrm{cm}) \times \text { age }(\text { years })
\end{aligned}
$$

$$
\begin{aligned}
\text { Women }: & 655+9.6 \times \text { body weight }(\mathrm{kg})+1.9 \\
& \times \text { body height }(\mathrm{cm})-4.7 \times \text { age }(\text { years })
\end{aligned}
$$




\section{Restraint questionnaires}

The three-factor eating questionnaire (German version according to Pudel and Westenhöfer ${ }^{28}$, original version according to Stunkard and Messick ${ }^{29}$ ) was used to test the psychological aspects of eating behaviour. The restraint scale could reach a score from 0 (no restraint) to 21 (extreme restraint); the disinhibition scale had a score from 0 (no disinhibition) to 16 (extreme disinhibition). The restraint sub-scale measures the tendency of an individual to restrict food intake in order to lose weight or to prevent weight gain. The disinhibition sub-scale assesses the tendency to overeat as a consequence of several environmental or emotional cues. A third scale with 14 items measures the degree of feelings of hunger. This scale was not included in this study.

\section{Statistical analysis}

Data analysis was performed using the StatView ${ }^{\circledR}$ package. Results are given for the mean and standard deviation (SD), and Pearson correlation coefficients were calculated between variables. In addition, stepwise multiple regression analysis was carried out to test whether the effects were influenced by other variables.

\section{Results}

Energy and macronutrient intakes, energy expenditure and the deviation between energy intake and expenditure are shown in Table 2. Data are given for the whole study population and for 'normal reporters' and 'underreporters' separately. Sex differences were observed for energy intake, energy expenditure (REE, TEE) and the deviation between both factors, but not for macronutrient intakes when expressed as percentage of energy intake (Table 2).

In a subgroup of subjects, TEE as derived from doubly labelled water served as the reference method. Comparing the individual values and the means (see Table 3), it is evident that there is a great variation in the data and assessments of TEE from measurements of REE. The data obtained by the physical activity (PA) protocol overestimated the degree and prevalence of underreporting (see Table 2). Reclassification of physical activity into three different levels of activity (activity factor (AF): sedentary, moderate and high) did not reduce the discrepancies. Using a fixed physical activity level together with the measurement of REE, the degree of underreporting was underestimated but the problem of overreporting physical activity was avoided (Table 2). Using DLW, three of seven subjects showed significant underreporting (i.e. EI - TEE > 20\%), whereas overreporting was seen in one subject. By contrast, use of REE $\times$ PA results in severe underreporting in six of seven subjects, whereas only one underreporting subject was identified when EI data were compared with $\mathrm{REE} \times \mathrm{AF}$. We decided to use a mean activity factor (1.55) instead of the data from the activity record, because this approach avoided the confounding 
Table 2 Energy intake and energy expenditure data for women and men

\begin{tabular}{|c|c|c|c|c|c|c|}
\hline & \multicolumn{3}{|c|}{ Women $(n=55)$} & \multicolumn{3}{|c|}{ Men $(n=28)$} \\
\hline & All women $(n=55)$ & $\begin{array}{l}\text { 'Normal } \\
\text { reporters' } \\
(n=28)\end{array}$ & $\begin{array}{c}\text { 'Underreporters' } \\
(20 \% \text { and more }) \\
(n=27)\end{array}$ & All men $(n=28)$ & $\begin{array}{l}\text { 'Normal } \\
\text { reporters' } \\
(n=24)\end{array}$ & $\begin{array}{c}\text { 'Underreporters' } \\
(20 \% \text { and more }) \\
(n=4)\end{array}$ \\
\hline \multicolumn{7}{|l|}{ Energy intake (kJ/24 h) } \\
\hline El & $8277 \pm 2060$ & $9374 \pm 1725$ & $6502 \pm 1080^{a}$ & $12615 \pm 2257^{\star}$ & $13046 \pm 2077$ & $10053 \pm 1599^{b}$ \\
\hline \multicolumn{7}{|l|}{ Macronutrient intake (\% of energy intake) } \\
\hline Carbohydrates & $47.7 \pm 6.6$ & $47.9 \pm 6.3$ & $47.4 \pm 7.3$ & $45.6 \pm 7.7$ & $45.5 \pm 7.9$ & $46.0 \pm 7.4$ \\
\hline Fat & $34.6 \pm 6.1$ & $34.6 \pm 5.6$ & $34.7 \pm 7.0$ & $35.7 \pm 5.6$ & $36.3 \pm 5.7$ & $32.8 \pm 4.5$ \\
\hline Protein & $14.4 \pm 2.6$ & $14.1 \pm 2.5$ & $14.8 \pm 2.8$ & $14.9 \pm 2.4$ & $14.9 \pm 2.2$ & $15.3 \pm 3.7$ \\
\hline Alcohol & $4 \pm 3.6$ & $4.0 \pm 3.8$ & $4.0 \pm 3.5$ & $4.5 \pm 3.5$ & $4.2 \pm 3.4$ & $6.1 \pm 4.5$ \\
\hline \multicolumn{7}{|l|}{ Energy expenditure $(\mathrm{kJ} / 24 \mathrm{~h})$} \\
\hline REE† & $5807 \pm 565$ & $5774 \pm 586$ & $5862 \pm 536$ & $7603 \pm 799^{*}$ & $7528 \pm 804$ & $8060 \pm 699$ \\
\hline Physical activitył & $5736 \pm 1118$ & $5585 \pm 1160$ & $5979 \pm 1030$ & $3894 \pm 1842$ & $3994 \pm 1842$ & $3282 \pm 1968$ \\
\hline TEE§, Standard 1 (REE + physical activity) & $11539 \pm 1081$ & $11357 \pm 1115$ & $11835 \pm 977$ & $11342 \pm 1747$ & $11517 \pm 1816$ & $10292 \pm 672$ \\
\hline TEE ף, Standard 2 (REE × 1.55) & $9412 \pm 3546$ & $9240 \pm 1457$ & $9688 \pm 1361$ & $13013 \pm 2499^{*}$ & $12991 \pm 2604$ & $13138 \pm 2056$ \\
\hline $\mathrm{RQ} \|$ & $0.83 \pm 0.04$ & $0.84 \pm 0.04$ & $0.83 \pm 0.04$ & $0.83 \pm 0.05$ & $0.83 \pm 0.05$ & $0.81 \pm 0.07$ \\
\hline \multicolumn{7}{|c|}{ Deviation of energy intake and energy expenditure $(\mathrm{kJ} / 24 \mathrm{~h})$} \\
\hline EI - TEE, Method 1 (REE + physical activity) & $-3263 \pm 2257$ & $-1984 \pm 1771$ & $-5334 \pm 1141^{\mathrm{a}}$ & $1272 \pm 2211^{*}$ & $1524 \pm 2251$ & $-242 \pm 1248^{b}$ \\
\hline$\%$ & $-27.8 \pm 18.9$ & $-17.1 \pm 15.2$ & $-44.9 \pm 9.1^{\mathrm{a}}$ & $12.1 \pm 17.8^{*}$ & $14.6 \pm 17.6$ & $-2.6 \pm 12.0^{b}$ \\
\hline El - TEE, Method $2($ REE $\times 1.55)$ & $-1135 \pm 2089$ & $134 \pm 1394$ & $-3186 \pm 1189^{a}$ & $-398 \pm 2010^{*}$ & $54 \pm 1796$ & $-3086 \pm 612^{\mathrm{b}}$ \\
\hline$\%$ & $-11.2 \pm 21.8$ & $2.0 \pm 15.6$ & $-32.5 \pm 10.6^{\mathrm{a}}$ & $-3.1 \pm 15.4^{\star}$ & $0.4 \pm 13.5$ & $-23.4 \pm 2.8^{\mathrm{b}}$ \\
\hline
\end{tabular}

†REE - resting energy expenditure.

‡Activity protocol.

$\S$ Physical activity as calculated from physical activity record $-R E E_{\text {estimated }}+R E E_{\text {measured. }}$

१ REE $\times 1.55$.

$\| \mathrm{RQ}$ - respiratory quotient.

* Significant differences between women and men $(P<0.05)$.

${ }^{a}$ Significant differences between normal and underreporting women $(P<0.05)$.

${ }^{\mathrm{b}}$ Significant differences between normal and underreporting men $(P<0.05)$. 
Table 3 Energy expenditure and energy intake in the subgroup for which doubly labelled water measurements were taken

\begin{tabular}{|c|c|c|}
\hline & Mean (SD) & Range \\
\hline $\mathrm{REE}_{\mathrm{m}}(\mathrm{kJ} / 24 \mathrm{~h})$ & $5757( \pm 296)$ & 5393 to 6284 \\
\hline TEE $_{(\mathrm{DLW})}$, Standard $3(\mathrm{~kJ} / 24 \mathrm{~h})$ & $10396( \pm 2275)$ & 7126 to 12950 \\
\hline $\operatorname{TEE}_{(\mathrm{PA})}$, Standard $2(\mathrm{~kJ} / 24 \mathrm{~h})$ & $11798( \pm 493)$ & 10928 to 12284 \\
\hline TEE $_{(\mathrm{AF})}$, Standard $1(\mathrm{~kJ} / 24 \mathrm{~h})$ & $8922( \pm 458)$ & 8359 to 9741 \\
\hline $\operatorname{TEE}_{(\mathrm{DLW})} / \mathrm{REE}_{\mathrm{m}}$ & $1.80( \pm 0.35)$ & 1.27 to 2.18 \\
\hline El (kJ/24h) & $8587( \pm 1331)$ & 7126 to 10886 \\
\hline $\mathrm{TEE}_{(\mathrm{DLW})}-\mathrm{El}$, Method $3(\mathrm{~kJ} / 24 \mathrm{~h})$ & $2546( \pm 2754)$ & -1424 to 5568 \\
\hline $\operatorname{TEE}_{(\mathrm{PA})}-\mathrm{El}$, Method $2(\mathrm{~kJ} / 24 \mathrm{~h})$ & $4639( \pm 2109)$ & 1503 to 7009 \\
\hline $\mathrm{TEE}_{(\mathrm{AF})}-\mathrm{El}$, Method $1(\mathrm{~kJ} / 24 \mathrm{~h})$ & $335( \pm 1371)$ & -1813 to 2321 \\
\hline
\end{tabular}

$R E E_{m}$ - measured resting energy expenditure.

TEE $_{(\mathrm{DLW})}$ - total energy expenditure according to doubly labelled water measurements.

$\mathrm{TEE}_{(\mathrm{PA})}$ - total energy expenditure according to physical activity protocol

$\mathrm{TEE}_{(\mathrm{AF})}$ - total energy expenditure according to REE $\times 1.55$

$\mathrm{EI}$ - energy intake as assessed by the 7-day dietary record.

influence of overreporting and allowed the identification of severe underreporting.

Comparing EI and TEE (Standard 1) in the whole study population, no association between the two was found (Fig. 1). However, there was a close association between self-reported energy intake and energy expenditure as calculated according to Standard $2($ TEE $=$ REE $\times 1.55)$ $(r=0.72)$ (Fig. 2). Comparing self-reported energy intake and TEE in women and men separately, a stronger association was observed for men $(r=0.65)$ than for women $(r=0.32)$.

Looking at the deviation of EI and Standard 1, on the one hand, and that of EI and Standard 2 on the other, both standards seem to yield a similar result (Fig. 3). But a Bland-Altman plot sheds light on the fact that Standard 1 overestimates TEE and thus the degree of underreporting (Fig. 4).

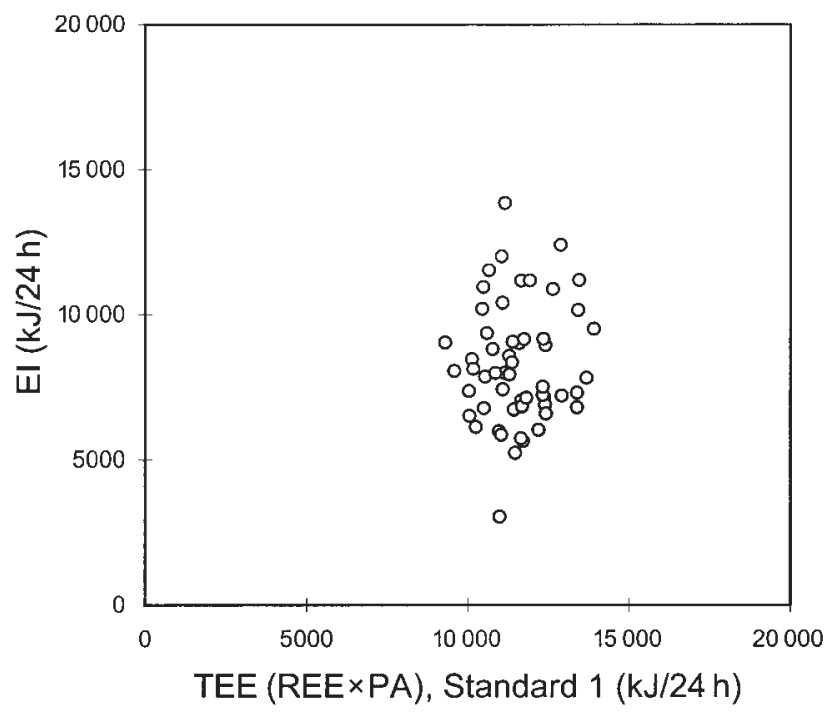

Fig. 1 Correlation between self-reported energy intake (El, 7dDR) and energy expenditure (TEE: REE $\times$ PA), Standard $1(n=83)$. EI - energy intake; 7dDR - 7-day dietary record; TEE - 24-hour energy expenditure; REE - resting energy expenditure; PA physical activity according the physical activity protocol

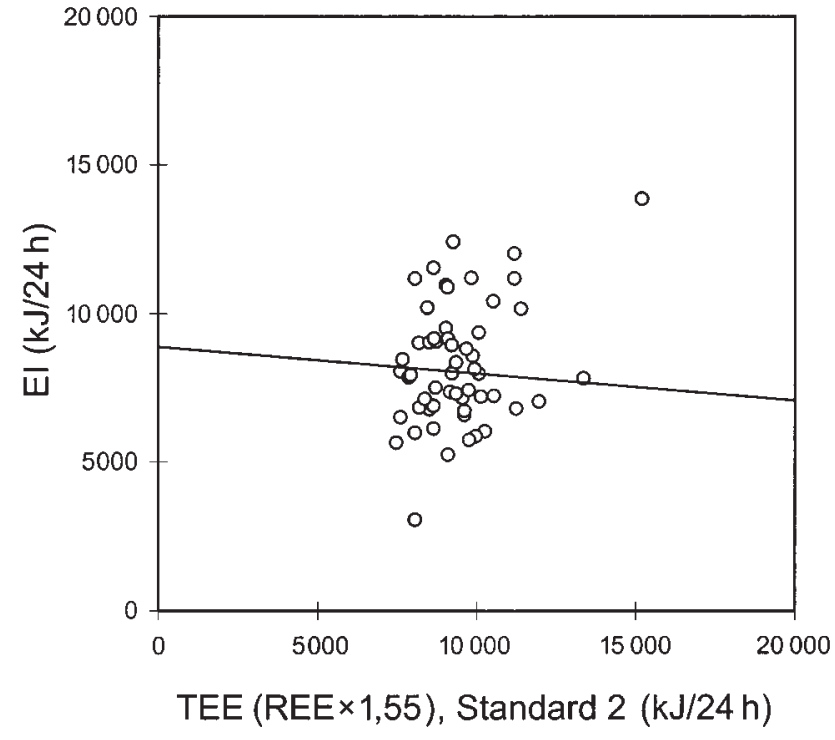

Fig. 2 Correlation between self-reported energy intake (EI, 7dDR) and energy expenditure (TEE: REE $\times 1.55)$, Standard $2(n=83)$. El - energy intake; 7dDR - 7-day dietary record; TEE - 24-hour energy expenditure; REE - resting energy expenditure

With respect to the deviation of self-reported energy intake and TEE (Standard 2), there was a wide variation in the data (Fig. 5, Table 2). In the whole study population, the prevalence of severe underreporting is $37 \%$ but sex differences were observed, i.e. $14.3 \%$ of men and $49 \%$ of women (Fig. 5). We found seven overreporting subjects (as defined EI - TEE > 20\%) in the sample. They did not differ significantly in any of the parameters measured and were thus enclosed in the 'normal reporting' group. For details of the overreporting population see Table 1 .

With respect to eating behaviour, all subjects reached on

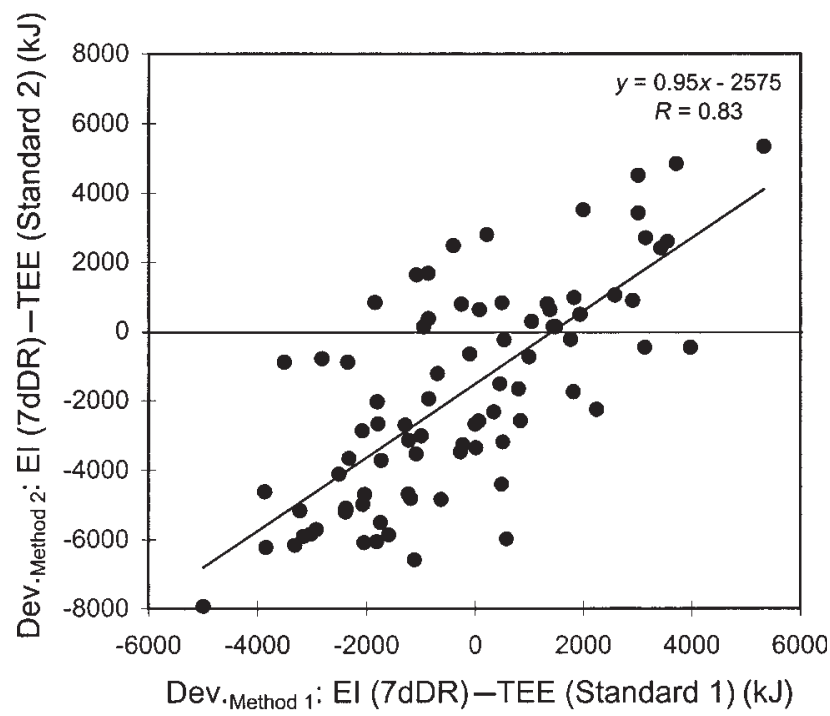

Fig. 3 Correlation between the deviation (Dev.) of EI and TEE $(T E E \times P A)$, Standard 1 , and the deviation of EI and TEE (REE $\times 1.55)$, Standard 2 ( $n=83)$. El - energy intake; 7dDR 7-day dietary record; TEE - 24-hour energy expenditure; REE resting energy expenditure; PA - physical activity according the physical activity protocol 
688



Fig. 4 Bland-Altman plot for the two different deviations (Dev.) of energy intake and energy expenditure. Method 1: EI (7dDR) TEE (REE × PA); Method 2: EI (7dDR) - TEE (REE × 1.55). EI energy intake; 7dDR - 7-day dietary record; TEE - 24-hour energy expenditure; REE - resting energy expenditure; PA physical activity according the physical activity protocol

average 6.4 points on the restraint scale and 5.3 points on the disinhibition scale (women: restraint 6.5, disinhibition 5.2; men: restraint 6.4, disinhibition 5.6).

More pronounced underreporting was observed the higher the subject's cognitive restraint $(r=-0.32$, $P<0.05)$. This tendency was consistent for men and women, although it did not reach significance in the subsamples due to the smaller sample size. In addition, in men, but not in women, underreporting was stronger the more disinhibition was reported. This is shown by a significant correlation between the deviation of selfreported energy intake and calculated energy expenditure on the one hand and three-factor eating questionnaire variables on the other (see Table 2 and Figs. 6 and 7).

Stepwise regression analyses with all other variables did not show a different result, as only the two reported

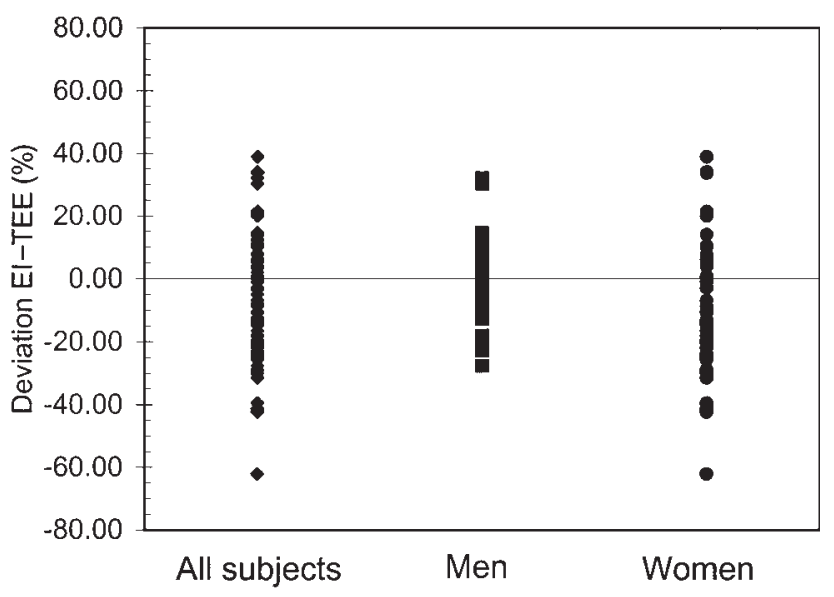

Fig. 5 Deviation of self-reported energy intake and energy expenditure as estimated from Standard 2. EI - energy intake; TEE 24-hour energy expenditure
I Asbeck et al.

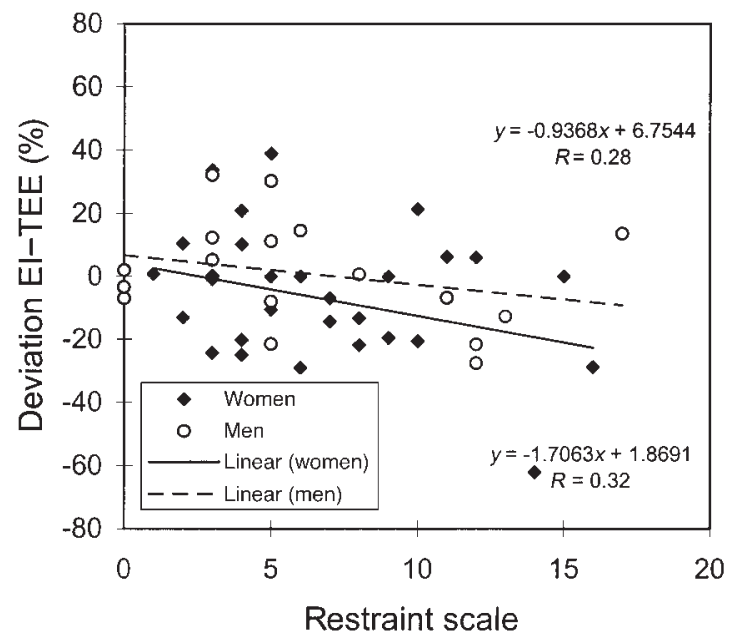

Fig. 6 Relationship between the deviation of energy intake (EI) and 24-hour energy expenditure (TEE) and cognitive restraint for men and women (three-factor eating questionnaire was administered to 50 subjects)

predictors (restraint in total study population, disinhibition in men) increased the multiple correlation significantly (Table 4).

\section{Discussion}

The main result of this study is that substantial underreporting occurred in $37 \%$ of non-obese, weight-stable subjects. Psychological aspects of eating behaviour were associated with underreporting and may have had an influence. A high cognitive restraint in men and women and a high level of disinhibition in men were associated with severe underreporting. Underreporting was stronger the higher the score on the restraint scale (Table 4). This means that the more the subjects decreased their food

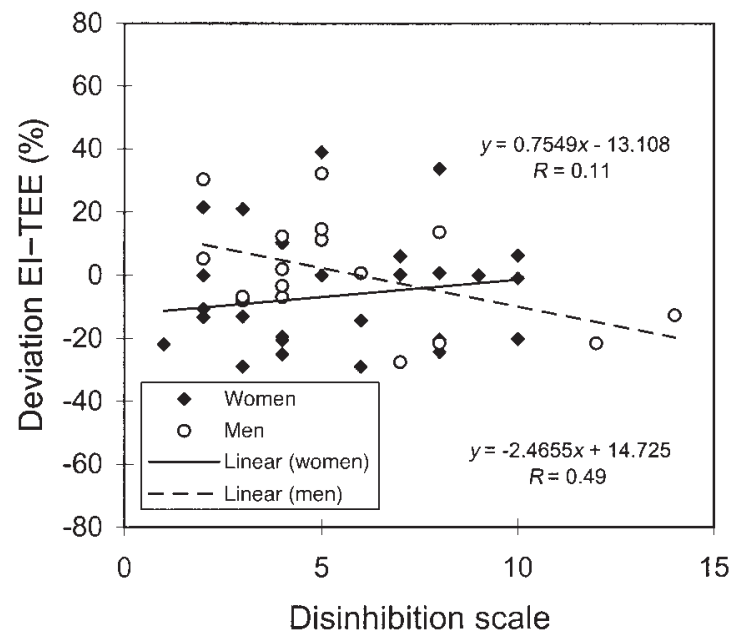

Fig. 7 Relationship between the deviation of energy intake (EI) and 24-hour energy expenditure (TEE) and disinhibition for men and women (three-factor eating questionnaire was administered to 50 subjects) 
Table 4 Product moment correlation between (7dDR - TEE) and variables of eating behaviour

\begin{tabular}{llc}
\hline & & 7dDR - TEE \\
\hline Women & Restraint & -0.33 \\
& Disinhibition & 0.11 \\
Men & BMI & -0.26 \\
& Restraint & -0.32 \\
& Disinhibition & $-0.53^{*}$ \\
Total study population & BMI & -0.26 \\
& Restraint & $-0.32^{*}$ \\
& Disinhibition & -0.12 \\
& BMI & -0.16 \\
\hline
\end{tabular}

7dDR - 7day-dietary record.

TEE - total energy expenditure as assessed by REE (resting energy expenditure) $\times 1.55$.

BMI - body mass index.

${ }^{*} P<0.05$.

intake (presumably in order to lose weight or not put on any weight), the higher was their degree of underreporting. Although the prevalence of underreporting showed sex differences ( $14.3 \%$ in men, $49 \%$ in women), this tendency was consistently seen in men and women.

There are two possible explanations for this phenomenon. First, increased self-observation when writing a dietary record increases the subject's self-control. Dietary intake is being decreased and this decrease might be stronger in persons with high restraint. Second, it is also possible that subjects with a high restraint have the selfimage of being very capable of controlling and decreasing their dietary intake. Our results are in line with results from a previous study by Poppitt et ll $^{12}$, who showed a higher cognitive restraint to be predictive of a higher degree of underreporting when studying energy intake and energy expenditure in obese and non-obese women. Such an association has also been shown by de Castro et al. ${ }^{17}$ : their study showed that comparable restraint levels result in similar energy intakes. However, these authors did not use a standard for energy intake. Bingham et al. ${ }^{18}$ validated a weighed dietary record using the 24-hour urine nitrogen technique and other biological markers in 160 women. They divided their study population into quintiles of the urinary nitrogen/dietary nitrogen ratio and found that individuals in the top quintile of the distribution were more restrained than other individuals. These data also suggest an association between underreporting and cognitive restraint. In our study an additional explanation for underreporting was seen in men. There was a higher degree of underreporting the more the men reported on disinhibition within the three-factor eating questionnaire. It is possible that this higher disinhibition leads to uncontrolled eating that is not recorded. This finding is contrary to those of Bingham et al., who did not find an association between the disinhibition score and underreporting in their study ${ }^{18}$.

The use of a standard in interpreting self-reported energy intake data is basic in the definition of 'underreporting'. The doubly labelled water method has been used for the measurement of TEE in free-living subjects and it can serve as a reference for EI under weight-stable conditions ${ }^{7}$. As it is a rather expensive and time-consuming method, its use is limited to small numbers of subjects ${ }^{30}$. In field studies, where large samples are being measured, other standards have to be used. It is evident that most studies on the effect of eating behaviour on self-reported energy intake have not used an appropriate standard ${ }^{12,17,20}$. In our study, REE was measured in all subjects and an activity protocol or an activity factor was used to calculate TEE. In addition, TEE as derived from doubly labelled water was measured and compared with calculated TEE in a subgroup of subjects (see Methods, Table 3). However, in this subgroup calculated data of TEE showed only a poor agreement with the DLW data (Table 3). Faced with these results and taking into account a possible overestimation of physical activity in an activity protocol as a confounding factor ${ }^{3}$, we decided to use a constant activity factor of 1.55. Looking at the sub-sample of seven subjects, the use of different standards leads to different magnitudes of underreporting. Using REE $\times 1.55$ as the standard, underreporting in $11.2 \%$ of women and $3.1 \%$ of men was seen. Using doubly labelled water as the standard, on average $19.3 \%$ of energy intakes were underreported. The activity record brought up even higher degrees of underreporting (on average $27.8 \%$ in women). The latter number may be explained by an overestimation of physical activity. Using different standards also affects the prevalence of underreporting (results). It should be mentioned that with respect to DLW measurements there might also be methodological problems (e.g. use of the Zn-reduction method as we did here often results in high D/O ratios). Alternatively, urinary nitrogen excretion was used as a validation criterion to show underreporting ${ }^{18}$. However, nitrogen excretion can serve as a reference standard for protein intake but not for energy intake. It is obvious that using estimates or measures of TEE as a reference for EI under weight-stable conditions may introduce further problems with respect to the magnitude and also the estimation of the prevalence of underreporting. This problem cannot be answered on the basis of the present data. In practice, the use of REE $\times 1.55$ (Standard 2) allows the identification of severe underreporting and shows an association with EI (Fig. 2). Standard 1 may overestimate underreporting because of an overestimation of physical activity in some subjects. In addition, Standard 1 did not show an association with EI (Fig. 1).

In conclusion, psychological aspects of eating behaviour should always be assessed together with dietary intake measurements. Restraint in all subjects and disinhibition in men are possible predictors for severe underreporting. For field studies, an appropriate standard for the assessment of energy intake remains to be established. 


\section{Acknowledgement}

The authors wish to thank Professor Dr E. Wisker for her help while performing the DLW studies.

\section{References}

1 Körtzinger I, Bierwag A, Mast M, Müller MJ. Dietary underreporting: validity of dietary measurements of energy intake using a 7-day dietary record and a diet history in nonobese subjects. Ann. Nutr. Metab. 1997; 41: 37-44.

2 Heitmann BL. The influence of fatness, weight change, slimming history and other lifestyle variables on diet reporting in Danish men and women aged 35-65 years. Int. J. Obes. 1993; 17: 329-36.

3 Lichtman SW, Pisarska K, Berman ER, Pestone M, Dowling $\mathrm{H}$, Offenbacher E, Weisel H, Heshka S, Matthews DE, Heymsfield SB. Discrepancy between self-reported and actual caloric intake and exercise in obese subjects. N. Engl. J. Med. 1992; 327: 1893-8.

4 Livingstone BE, Prentice AM, Coward WA, Ceesay SM, Strain JJ, McKenna PG, Nevin GB, Barker ME, Hicker RJ. Simultaneous measurement of free-living energy expenditure by doubly labelled water method and heart-rate monitoring. Am. J. Clin. Nutr. 1990; 52: 59-65.

5 Hulten B, Bengtsson C, Isaksson B. Some errors inherent in a longitudinal dietary survey revealed by the urine nitrogen test. Eur. J. Clin. Nutr. 1990; 44: 169-74.

6 Prentice AM, Black AE, Coward WA, Davies HL, Goldberg GR, Murgatroyd PR, Ashford J, Sawyer M, Whitehead RG. High levels of energy expenditure in obese women. $\mathrm{Br}$. Med. J. 1986; 292: 983-92.

7 Schoeller DA. How accurate is self-reported dietary intake? Nutr. Rev. 1990; 48: 373-9.

8 Singh J, Prentice AM, Diaz E, Coward WA, Ashford J, Sawyer M, Whitehead RG. Energy expenditure of Gambian women during peak agricultural activity measured by the doublylabelled water method. Br. J. Nutr. 1989; 62: 315-29.

9 Mertz W, Tsui JC, Judd JT, Reiser S, Hallfrisch J, Morris ER, Steele PD, Lashley E. What are people really eating? The relation between energy intake derived from estimated diet records and intake determined to maintain body weight. Am. J. Clin. Nutr. 1991; 54: 291-5.

10 Westerterp KR, Saris WHM, van Es M, ten Hoor F. Use of doubly labeled water technique in humans during heavy sustained exercise. J. Appl. Physiol. 1986; 61: 2162-7.

11 Haggarty P, McGaw BA, Maughan RJ, Fenn C. Energy expenditure of elite female athletes measured by the doublylabelled water method. Proc. Nutr. Soc. 1988; 47: 35A.

12 Poppitt SD, Swann D, Black AE, Prentice AM. Assessment of selective under-reporting of food intake by both obese and non-obese women in a metabolic facility. Int. J. Obes. 1998; 22: 303-11.

13 Riumallo JA, Schoeller DA, Barrera G, Gattas V, Uauy R. Energy expenditure in underweight free-living adults: impact of energy supplementation as determined by doubly-labeled water and indirect calorimetry. Am. J. Clin. Nutr. 1989; 49: 239-46.

14 Bandini LG, Schoeller DA, Dietz WH. Energy expenditure in obese and nonobese adolescents. Pediatr. Res. 1990; 27: $198-203$
15 Prentice AM, Coward WA, Davies HL, Murgatroyd PR, Black AE, Goldberg GR, Ashford J, Sawyer M, Whitehead RG. Unexpectedly low levels of energy expenditure in healthy women. Lancet 1985; 22: 1419-22.

16 Livingstone MBE, Prentice AM, Strain JJ, Coward WA, Black AE, Barker ME, McKenna PG, Whitehead RG. Accuracy of weighed dietary records in studies of diet and health. $\mathrm{Br}$. Med. J. 1990; 300: 708-12.

17 de Castro JM. The relationship of cognitive restraint to the spontaneous food and fluid intake of free-living humans. Physiol. Behav. 1985; 57: 287-95.

18 Bingham SA, Cassidy A, Cole TJ, Welch A, Runswick SA, Black AE, Thurnham D, Bates C, Khaw KT, Key T, Day NE. Validation of weighed records and other methods of dietary assessment using the $24 \mathrm{~h}$ urine nitrogen technique and other biological markers. Br. J. Nutr. 1995; 73: 531-50.

19 Black AE, Jebb SA, Bingham SA, Runswick SA, Poppitt SD. The validation of energy and protein intakes by doubly labelled water and 24-h urinary nitrogen excretion in postobese subjects. J. Hum. Nutr. Diet. 1995; 8: 51-64.

20 Price GM, Paul AA, Cole TJ, Wadsworth MEJ. Characteristics of the low energy reporters in a longitudinal national dietary survey. Br. J. Nutr. 1997; 77: 833-51.

21 Cameron ME, van Staveren WA, eds. Manual on Methodology for Food Consumption Studies. Oxford: Oxford University Press, 1988.

22 Müller MJ, vz Mühlen A, Lautz HU, Schmidt FW, Daiber M, Hürter P. Energy expenditure in children with type I diabetes: evidence for increased thermogenesis. $\mathrm{Br}$. Med. J. 1989; 299: 487-91.

23 Schofield EC, Dallosso HM, James WPT. Energy cost of physical activity classified in alphabetical order. In: James WPT, Schofield EC, eds. Human Energy Requirements. A Manual for Planners and Nutritionists. Oxford: University Press, 1990; 133-5.

$24 \mathrm{FAO} / \mathrm{WHO} / \mathrm{UNU}$. Energy and Protein Requirements. Report of a Joint FAO/WHO/UNU Consultation. WHO Technical Report Series 724. Geneva: World Health Organization (WHO), 1985

25 Schoeller D, Coward A. Isotope fractionation corrections. In: Prentice A, ed. The Doubly-Labelled Water Method for Measuring Energy Expenditure. A Consensus Report by the IDECG Working Group, 1990; 90-110.

26 Jiang ZQ, Yan Q, Su YX, Acheson KJ, Thelin A, PiguetWelsch C, Ritz P, Ho ZC. Energy expenditure of Chinese infants in Guangdong province, south China, determined with use of doubly labelled water method. Am.J. Clin. Nutr. 1998; 67: 1256-64.

27 Elia M. Converting carbon dioxide production to energy expenditure. In: Prentice A, ed. The Doubly-Labelled Water Method for Measuring Energy Expenditure. A Consensus Report by the IDECG Working Group, 1990; 193-211.

28 Pudel V, Westenhöfer J. Fragebogen zum Eßverhalten: Handanweisung. Göttingen: Hogrefe, 1989.

29 Stunkard AJ, Messick S. The three-factor eating questionnaire to measure dietary restraint, disinhibition and hunger. J. Psychosomatic Res. 1985; 29: 71-83.

30 Murgatroyd PR, Shetty PS, Prentice AM. Techniques for the measurement of human energy expenditure. Int. J. Obes. 1993; 17: 549-68. 